\title{
BRINGING CHEMISTRY CLOSER: CREATING A 'LIVING PERIODIC TABLE’ FOR USE IN GENERAL AND INORGANIC CHEMISTRY EDUCATION
}

\author{
"KATEŘINA RUBEŠOVÁ, DANA MIKOLÁŠOVÁ, VÍT JAKEŠ \\ Department of Inorganic Chemistry, University of Chemistry and Technology, \\ Technická 5, Prague 6, 16628, Czech Republic \\ "E-mail: rubesovk@vscht.cz
}

Submitted June 14, 2019; accepted August 26, 2019

\begin{abstract}
Keywords: Periodic table, Lewis acids/bases, HSAB principle, Inorganic chemistry, Teaching tool
Because nature presents 'a laboratory of chemical equilibria', the examples and patterns taken from nature can be used in the education of general and inorganic chemistry. We have compiled the collection of elements and their stable natural forms and we are going to use it in the undergraduate seminars of inorganic chemistry. Here, we propose some trends in physical and chemical properties of elements and compounds that can be demonstrated in the seminars standing in front of our collection (e.g. trends in melting and boiling points, stable oxidation states, bonding preferences of elements). In current overflow of electronic educational materials, such a visual activity can be refreshing for both students and teachers. And last but not least, the collection and this article is meant as our contribution to the $150^{\text {th }}$ anniversary of Dmitriy Ivanovich Mendeleev's presentation of the periodic table.
\end{abstract}

\section{INTRODUCTION}

As a visual icon, the periodic table is a powerful tool for understanding chemistry - pupils start their chemistry education by learning the names and symbols of the elements, periodic table posters hang on the wall of every chemistry classroom and chemistry books give the periodic table pride to place. At a deeper level, the periodic table provides answers to many questions about the chemical and physical properties of elements and their compounds. To mark the $150^{\text {th }}$ anniversary of Dmitriy Ivanovich Mendeleev's presentation of the periodic table [1-2], the United Nations General Assembly and UNESCO proclaimed 2019 as "the International Year of the Periodic Table of Chemical Elements (IYPT2019)" [3]. To contribute to the celebration of IYPT2019, we have collected the samples and their stable natural forms whose exhibition is going to be used at the general and inorganic chemistry education.

The idea to collect and display samples of elements is not new nor is the collection of natural forms of elements an original concept [4-5]. Nowadays, complete collections of elements are commercially available [6]; such sets are beautiful, on the other hand, a bit 'impersonal'. The actual joy for a chemist is in searching for exhibits (in their personal collection, among friends, on the internet, etc.) and deciding which exhibits best represent a particular element. In short, a periodic table built from zero has a history dear to all those who participate in its creation. Moreover, such a table can be used to further the education of general and inorganic chemistry. Here at the University of Chemistry and Technology Prague (UCT), General and Inorganic Chemistry I is a compulsory course for all undergraduates, with approximately 1000 students enrolling per year. The course is divided into lectures and seminars, the latter of which are taught in smaller groups that facilitate the development of a 'living periodic table'.

\section{DISCUSSION}

Elements and natural forms exhibition

Our exhibition is presented as a shelf in the shape of the periodic table and made of wood covered by lockable glass. Each compartment is labelled with the element symbol, atomic number, and Czech and English name. The largest space in each compartment is reserved for a sample of elemental form (e.g. sodium) and one or more 
samples of compounds commonly occurring in nature (e.g. halite and sodalite, in the case of sodium), with the focus on primary minerals if available. The natural form is described by its chemical formula and Czech name, typical compartments being depicted in Figure 1a. However, there are some atypical compartments. For example, the 28 f-block elements are represented by one compartment for Lanthanides (La-Lu) and one for Actinides (Ac-Lr), as shown in Figure 1b. The compartments of the $7^{\text {th }}$ period, being composed only of artificially synthetized and unstable elements, are presented by the half-time of the most stable isotope, with no samples present (Figure 1c).

The greatest challenge in the collection of such an exhibition is to accept the fact that some elements can be represented by a number of samples (e.g. silicon forms a large number of both crystalline and amorphous varieties of quartz), all of which may be beautiful, but not all of which can be accommodated in the compartment. On the other hand, some elements have limited options for exhibition; for example, highly noble metals are mostly found in nature in metallic form and obtaining a representative piece is neither easy nor cheap.

\section{Use of 'living periodic table' in inorganic chemistry education}

The structured presentation of the elements in their physical form is inspiring for even the most hardened chemist. Moreover, seeing a real table of elements is a great way for undergraduate students to learn about chemical and physical properties and their periodicity. It imprints a visual memory in students that strengthens their basic knowledge. Moreover, such a visual activity can counterbalance the current overflow of electronic educational materials.

The following themes can be demonstrated when students visit the exhibition as a part of a seminar:
First insight into the periodic table

At the beginning of the session, it is important to spark the students' interest, for instance by setting them a short quiz; the example questions with answers in brackets:

- guess 12 elements known in ancient times from 118 being described nowadays $(\mathrm{C}, \mathrm{S}, \mathrm{Fe}, \mathrm{Cu}, \mathrm{Zn}, \mathrm{As}, \mathrm{Ag}$, $\mathrm{Sn}, \mathrm{Sb}, \mathrm{Au}, \mathrm{Hg}$ and $\mathrm{Pb}$ )

- estimate what percentage of elements belongs to metals (approx. $75 \%$; only few students realize that the majority of the periodic table comprises of metals; the samples of metals are mostly shiny, so the answer becomes clear very quickly)

- the periodic table contains 118 confirmed elements up to date; how many of them were synthetized artificially (24)

- which group of elements was missing in the periodic table proposed by Mendeleev in 1869 (the $18^{\text {th }}$ group of noble gases; it is believed to be one of reasons why Mendeleev did not obtain the Nobel Prize in Chemistry for his otherwise great work)

- which of the following items is not approved as a potential name theme after which a new element can be named: geographical name, scientist name, politician name, mythology (politician name; the naming of new elements can be shown within the $7^{\text {th }}$ period)

\section{Trends in boiling and melting points of elements}

One of physical properties, which is often governed by periodicity, is boiling (or melting) point. However, several factors affect the boiling and melting points of substances. In the case of gaseous and liquid nonmetals, London dispersion forces (dependent on the

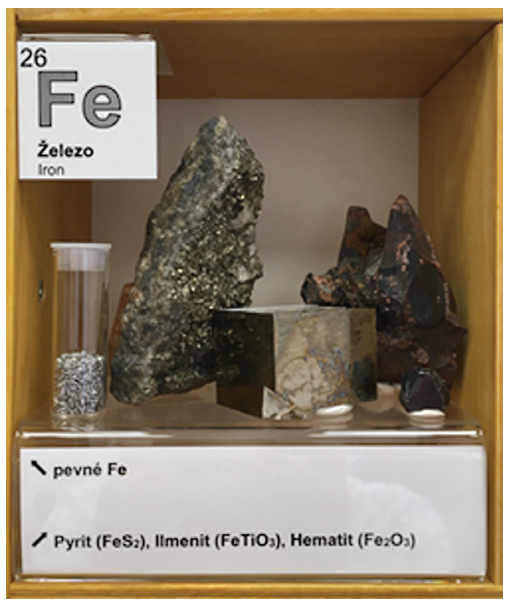

a) elemental and nature forms

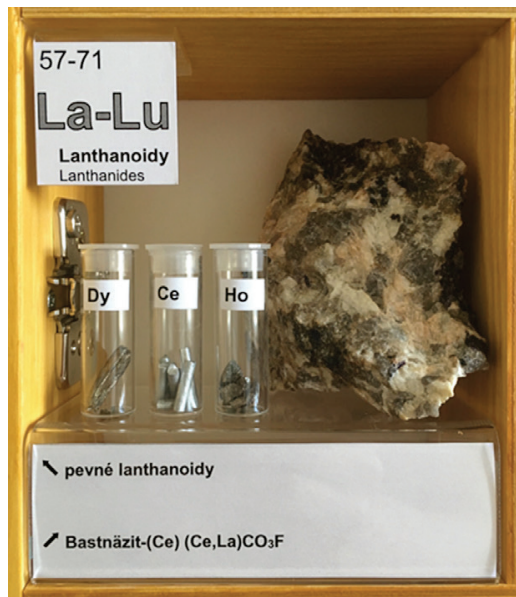

b) Lanthanides
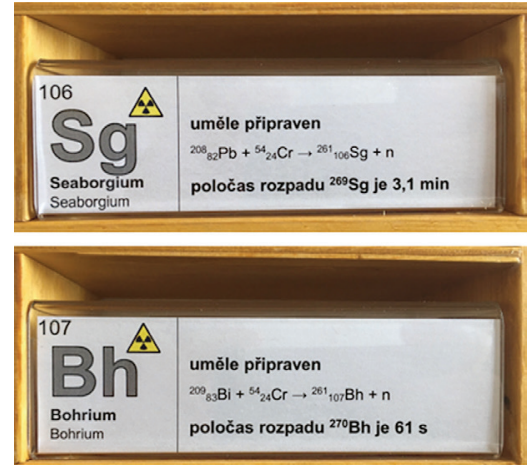

c) radioactive elements without real samples

Figure 1. Examples of exhibition compartments - typical compartments of elemental and nature forms (a), shortened compartment of Lanthanides (b) and examples of radioactive elements without real samples (c). 
polarizability of an electron shell) determine their melting and boiling points. In the case of solid nonmetals, the energy of the crystal lattice is the driving factor, as well as in the case of metals. In teaching this, the following facts can be demonstrated in relation to the exhibition:

- halogens are the only periodic table group that, at laboratory temperature, contains elements in all three phases $\left(\mathrm{F}_{2}\right.$ and $\left.\mathrm{Cl}_{2}(\mathrm{~g}), \mathrm{Br}_{2}(\mathrm{l}), \mathrm{I}_{2}(\mathrm{~s})\right)$; this fact is helpful when explaining the influence of atomic size (the polarizability of an electron shell and overall molecular mass) on the boiling and melting points

- the $18^{\text {th }}$ group is fully gaseous; noble gases do not form homo-atomic molecules, so only London dispersion forces between isolated atoms affect their boiling points; however, Og is predicted to be liquid

- at laboratory temperature, only 11 elements are gaseous, 2 are liquid and the rest are solid

- the melting temperature of elements is spread over an interval of approx. $4000^{\circ} \mathrm{C}$ (from $\mathrm{He}$ to $\mathrm{C}$ in the form of a diamond)

- two metallic elements can melt in the human hand: $\mathrm{Ga}$ and Cs with a melting point of 29.8 and $28.5^{\circ} \mathrm{C}$, re-spectively (for safety reasons, this should only be demonstrated with Ga)

\section{Similarity off-elements behaviour}

Lanthanides and Actinides are each merged into one slot due not only to a lack of space but also to their chemical behaviour being very similar. Explanation for students: The f-orbitals, especially $4 \mathrm{f}$, are attracted closer to the atomic nucleus as the effective nuclear charge increases. Because it is difficult to ionize more than 2 or 3 electrons, the most common oxidation state is +III. Therefore, the f-elements can be found in nature in co-doped minerals (mainly phosphates or carbonates) and their high price is due not only to their low abundance but also to the difficulty of their separation and purification.

\section{Natural forms of elements: demonstration of stable states and bonding preferences}

Nature can be perceived as a laboratory of longlasting experiments, the products of which are displayed in the exhibition, demonstrating perfect equilibrium. From the chemical point of view, the natural forms of the elements demonstrate stable oxidation states; for instance, if sodium and chlorine are exclusively present in nature as ions with a valence of $+\mathrm{I}$ and $-\mathrm{I}$, respectively, one can assume that these oxidation states are redox stable. Conversely, we can assume that elemental sodium and chlorine are strong reducing and oxidizing agents, respectively. Between these two extreme examples, for instance, sulphur is present as sulphides, elemental sulphur or sulphates, all of them being stable or, at least, meta-stable valences.

The chemical bonding preferences of elements are another quality that can be conveniently demonstrated using the natural forms of elements. One of the basic grouping of elements by bonding preference is the Goldschmidt classification [7]. This geochemical categorization sorts elements according to their preferences to i) lithophile (rock-forming elements bonding with oxygen), ii) siderophile (iron-loving elements found closer to the Earth's core), iii) chalcophile (bonding with chalcogens other than oxygen), and iv) atmophile (gaseous elements found in the atmosphere).

A more detailed classification according to bonding preference becomes possible when we consider the most stable minerals found in the lithosphere. Our 'living periodic table' enables trends to be explained by the Hard and Soft Acid Base principle (HSAB) [8-9]. Elements (or their cations) can be ordered from hard Lewis acids (low electron affinity, high energy LUMO) to soft Lewis acids (easily polarized, low energy LUMO). Apart from the element position in the periodic table, the oxidation state of a cation also has an important role in this classification $\left(\mathrm{Cu}^{\mathrm{I}}\right.$ is a soft Lewis acid, $\mathrm{Cu}^{\mathrm{II}}$ is borderline hard). The anions of the minerals can also be categorized according to their hardness; oxoanions and fluorides are hard Lewis bases (difficult to polarize or oxidize; high energy HOMO) while chalcogenides $\left(\mathrm{S}^{2-}\right.$, $\mathrm{Se}^{2-}, \mathrm{Te}^{2-}$ ), bromides and iodides belong to soft Lewis bases (easily polarized or oxidized, low energy HOMO). It can be thus demonstrated that soft acids prefer to combine with soft bases rather than with hard bases and vice versa. It should be pointed out that many minerals are stable due to the highly favourable lattice energy and/or the nobility of the metals.

The above-described preferences can be shown by reference to trends from the left to the right side of the periodic table (selected elements depict the overall trend in Figure 2):

- $1^{\text {st }}$ and $2^{\text {nd }}$ group cations are naturally found mainly in the form of silicates or alumino-silicates and carbonates; a special group of minerals is represented by the halides which have extraordinarily favourable lattice energy (Figure 2a)

- from the $2^{\text {nd }}$ group to the Lanthanides and the 3rd group of elements, we find minerals based on silicates, carbonates, phosphates and sulphates

- the $d$-block elements range from hard Lewis acids (e.g. Ti, Nb, Cr - Figure 2b) in the form of oxides or hydroxides to elements that are stable in nature both as oxides and chalcogenides (e.g. Mo, Fe - Figure 2c) 
up to extra noble metals mainly found in nature as pure metals, but sometimes as sulphides (e.g. Ag, $\mathrm{Hg}$ - Figure 2d); going further to the right brings us back to the region where we again find stable sulphides, selenides or tellurides, and oxides in some cases (e.g. $\mathrm{Zn}, \mathrm{Cu}$ )

- chalcogenides, rarely oxides, are also typical stable forms of p-block metals and metalloids (e.g. Pb, Bi - Figure 2e) with the exception of aluminium whose cation behaves as the hard acid preferring the bond with oxygen in oxides, aluminosilicates etc.

- at the very right side, non-metals are positioned as central atoms in anions (nitrates, phosphates, sulphates etc.) or are stable in gaseous form (Figure $2 \mathrm{f}$ ).

Furthermore, all of the above-described trends and facts are summarized in an A2 poster hanging nearby that complements our periodic table exhibition and can be used at the session. Besides, the stable natural forms of elements are summarized schematically (Figure 3) and put into parallel with the known picture of the distribution of soft-middle-hard Lewis acids over the periodic table. We believe that our 'living periodic table' will not only bring joy but also help students to better associate the nature of elements with their properties. The collection of real samples of elements and their natural forms has been already incorporated in the undergraduate level of general and inorganic chemistry education at the UCT.

\section{CONCLUSIONS}

The mineral composition of the Earth crust can serve as a natural textbook of the bonding preferences of the elements based on the hard and soft Lewis

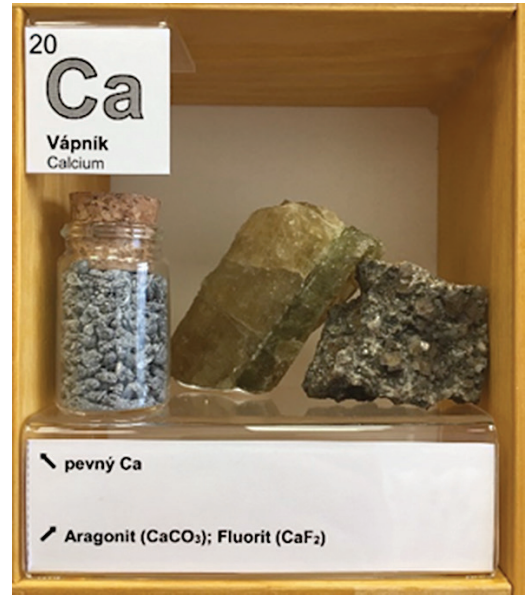

a)

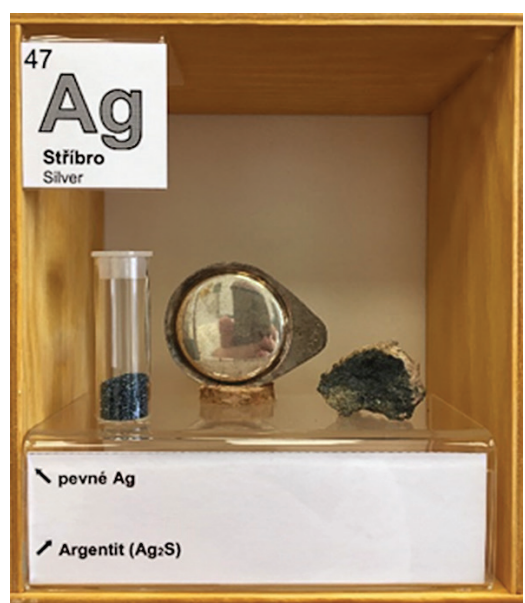

d)

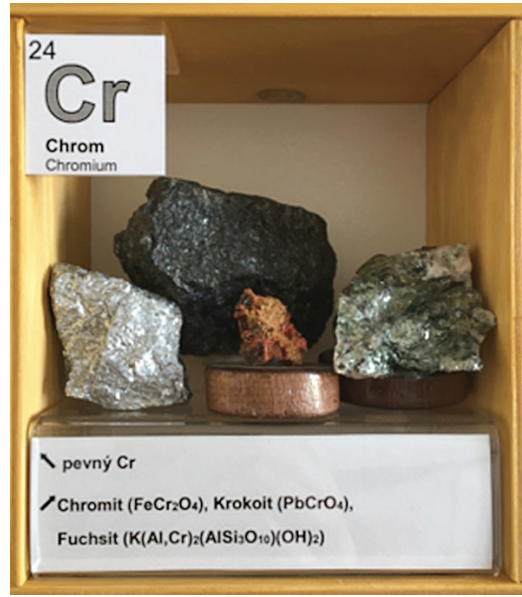

b)

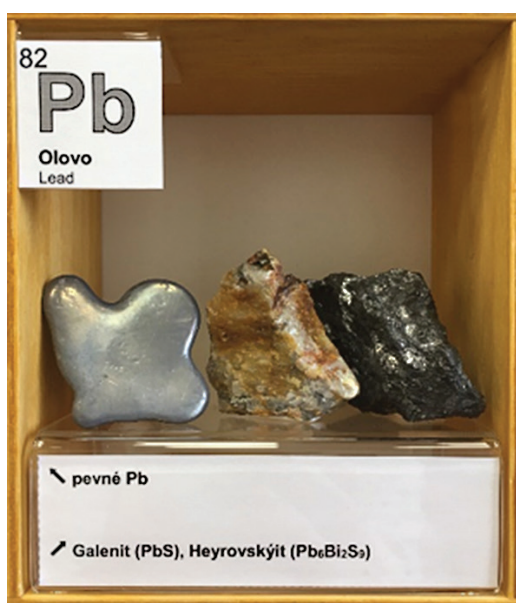

e)

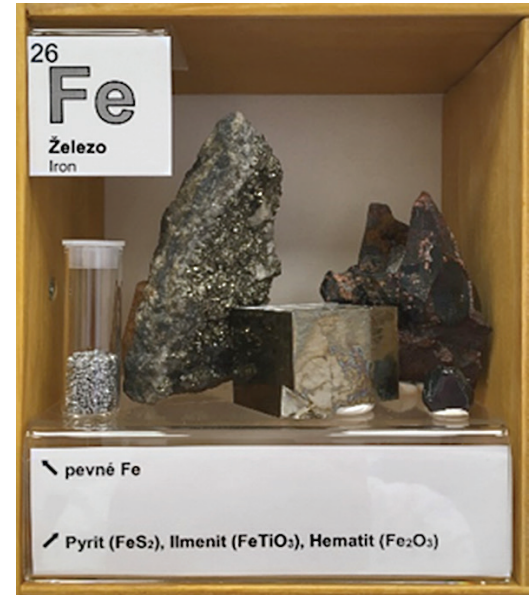

c)

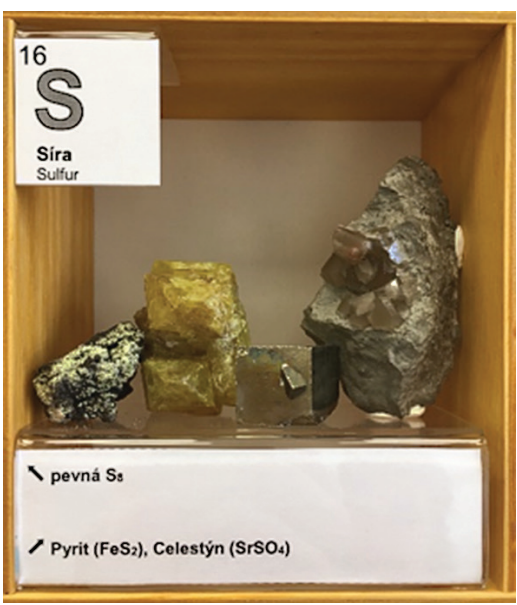

f)

Figure 2. Examples of sample sets demonstrating the change of bonding preferences going from the left to right side of the periodic table - the compartments of: a) Ca with Aragonite $\left(\mathrm{CaCO}_{3}\right)$ and Fluorite $\left(\mathrm{CaF}_{2}\right)$; b) Cr with Chromite $\left(\mathrm{FeCr}_{2} \mathrm{O}_{4}\right), \mathrm{Fuchsite}_{3}$ $\left(\mathrm{K}(\mathrm{Al}, \mathrm{Cr})_{2}\left(\mathrm{AlSi}_{3} \mathrm{O}_{10}\right)(\mathrm{OH})_{2}\right)$ and Crocoite $\left.\left(\mathrm{PbCrO}_{4}\right) ; \mathrm{c}\right)$ Fe with Pyrite $\left(\mathrm{FeS}_{2}\right)$, Ilmenite $\left(\mathrm{FeTiO}_{3}\right)$ and Hematite $\left(\mathrm{Fe}_{2} \mathrm{O}_{3}\right)$; d) $\mathrm{Ag}$ with Argentite $\left(\mathrm{Ag}_{2} \mathrm{~S}\right)$; e) $\mathrm{Pb}$ with Galenite $(\mathrm{PbS})$ and Heyrovskyite $\left(\mathrm{Pb}_{6} \mathrm{Bi}_{2} \mathrm{~S}_{9}\right)$; f) S with nature elemental sulphur, Pyrite $\left(\mathrm{FeS}_{2}\right)$ and Celestine $\left(\mathrm{SrSO}_{4}\right)$. 
acids and bases. This, together with the Periodic Table anniversary, inspired us to assemble 'Living Periodic Table' with exhibits from the collections of the Department of Inorganic Chemistry (UCT Prague) and private collections of our colleagues at the UCT Prague. Each compartment of the Table shows the elemental form and the most common geological form of the element, if the safety and availability permits. Our Living Periodic Table is now permanently installed at the Department of Inorganic Chemistry and has been successfully used in the courses of general and inorganic chemistry ever since.

\section{Acknowledgments}

We would like to dedicate this work to Olga Smrčková, Dagmar Sýkorová and Vratislav Flemr our teachers and later colleagues that showed us a way how to learn and, afterward, how to teach inorganic chemistry. The work was supported by the Internal Grant Agency of the University of Chemistry and
Technology as project CI VŠCHT 2018019 and the samples were mostly collected in a cooperation with other UCT departments; the collecting process has not yet finished.

\section{REFERENCES}

1. Lewis D.E. (2014): Citation for chemical breakthrough award: Mendeleev's periodic system of the elements. Bulletin For The History Of Chemistry, 39 (1), 1-6

2. Mendeleev D.I. (1969): Sootnoshenie svoistv s atomnym vesom elementov. Zhurnal Russkago Fiziko-Khimicheskago Obshchestva, 1, 60-77

3. UNESCO (2019). 2019 is proclaimed the International Year of the Periodic Table of Chemical Elements. https:// en.unesco.org/news/2019-proclaimed-international-yearperiodic-table-chemical-elements (accessed April 2019)

4. Marshall J.L. (2000): A Living Periodic Table. Journal of Chemical Education, 77 (8), 979. doi: 10.1021/ed077p979

5. Silva A., Barroso M.F., Freitas O., Teixeira S., Morais S., Delerue-Matos C. (2006): The Periodic Table: Contest and Exhibition. Journal of Chemical Education, 83 (4). 557. doi: 10.1021/ed083p557
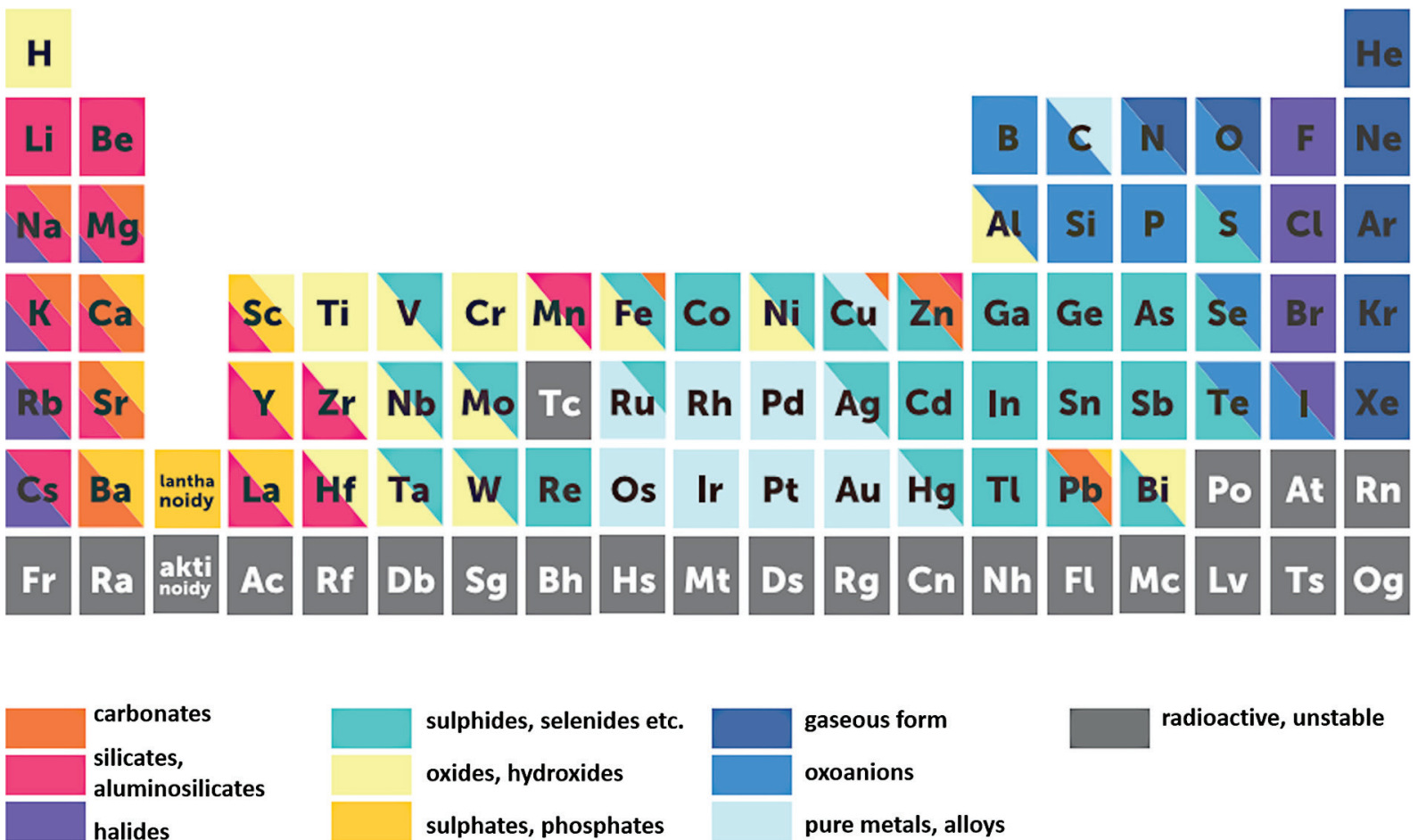

Figure 3. Schematic representation of the most common elements forms stable in nature. 
Rubešová K., Mikolášová D., Jakeš V.

6. periodictable.co.uk(2019).https://www.periodictable.co.uk/ (accessed April 2019)

7. Goldschmidt V.M. (1937): The principles of distribution of chemical elements in minerals and rocks. The seventh Hugo Müller Lecture, delivered before the Chemical Society on March 17th, 1937. Journal of the Chemical Society (Resumed), (0), 655-673. doi: 10.1039/JR9370000655

8. Pearson R.G.(1968): Hard and soft acids and bases HSAB
Part I, Fundamental principles Journal of Chemical Education, 45 (9), 581-587; doi: 10.1021/ed045p581

9. Pearson R.G. (1968): Hard and soft acids and bases hsab .2. underlying theories. Journal of Chemical Education, 45 (10), 643-648. doi: 10.1021/ed045p643 